\title{
Lectin histochemistry of epidermal glandular cells in the earthworm Lumbricus terrestris (Annelida Oligochaeta)
}

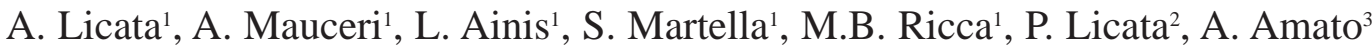

${ }^{1}$ Department of Animal Biology and Marine Ecology, University of Messina; ${ }^{2}$ Department of Pathology, Infection and Parasitic Diseases and Animal Origin Food Inspection, University of Messina; ${ }^{3}$ Chair of Cellular Biology, University of Messina.

Accepted: 5/2/2002

Key words: annelida, Lumbricus terrestris, epidermis, lectins, mucous cells

\section{SUMMARY}

Carbohydrate residues were localized in the glandular cells of the epidermis of Lumbricus terrestris by lectin histochemistry. The following biotinylated lectins were used: ConA, PNA, WGA, UEA-I. Each lectin has a specific binding pattern in the epidermal glandular cells. The ConA binding is evident in the orthochromatic mucous cells; PNA in the metachromatic mucous cells; WGA in the neuroendocrine-like cells; UEA-I in the cuticle. The epidermal glandular cells possess specific sites for the different lectins in relation to their functional characteristics. Therefore, these sugar residues indicate different behaviours of the cells in epidermal functions related to ion transport, receptor-secretory processes and defence.

\section{INTRODUCTION}

The glandular cells in the surface epithelia of invertebrates and vertebrates secrete a mucus composed of sugars and sialic acid residues involved in the reduction of cell pH (Kirschner, 1978). The glycoconjugates, essential components of the glycoca- lyx of many cell types, are involved in many functions including osmoregulation (Kirschner, 1978; Wendelaar-Bonga, 1978; Hughes, 1980; Zaccone et al., 2001), cell to cell recognition, binding of hormones, protection of cells from phagocytosis and dehydration (Watt and Jones, 1992), differentiation, defence (Harris and Hunt, 1973; Fletcher, 1978) and ion transport, as demonstrated in lower vertebrates (Jeanloz and Codington, 1976; Glick and Flowers, 1978). In some epithelial cells, morphologically and functionally polarized in relation to different behaviours in ion transport (Spicer et al., 1981), it is possible observe a functional specialization of the glycoconjugates present on the baso-lateral surface; they are acidic, while those of the apical surface are neutral (Pisam and Ripoche, 1976; Fujimoto and Ogawa, 1983).

Recent studies have revealed a precise regionalization of the glycoconjugates in relation to different distribution of the endogenous receptors for these substances. In lower vertebrates, glycoconjugates with different structures have different polarization patterns (Navas et al., 1987; Zaccone et al., 1987; Villalba and Navas, 1989).

Specific functions have been rarely attributed to particular mucins produced by annelids. In many

Correspondence to: A. Licata

E-mail: alicata@unime.it 
stances are thought to act as an ion barrier, because of a selective or buffering ability. In addition, the mucous film absorbs heavy metals and delays their entry into the tegument (Richards, 1978).

Although the monostratified epidermis of the earthworm Lumbricus terrestris is well defined morphologically, the functional role of some of its specialized cells must still be clarified. In the epidermis of the oligochaete lumbricids, mucous and protein glandular cells are commonly found. However, the characterization of the mucous secretion in the two (orthochromatic and metachromatic) cell types has been investigated only with the conventional histochemical methods. The orthochromatic cells secrete a complex of neutral mucopolysaccharides, proteins and lipids (sulfomucins and glycogen are absent). Moreover, the dense orthochromatic granules, to which has been attributed a lubricating action during locomotion (Richards, 1973), may also contain a pheromone important in mating. On the contrary, the metachromatic cells produce a carboxylated slightly sulfated mucus, probably of low viscosity, which provides a respiratory film held to the surface of the cuticle by epicuticular projections (Richards 1974). It has not been determined if this secretion is equivalent to the non-sulfated mucopolysaccharide fraction identified biochemically and denominated oratine (Richards, 1978).

The third type of glandular cells, called "small granular cells", are rich in proteins and are scattered throughout the epidermis. The secretion of these cells could aid water retention in the acidic mucous film or modify the viscosity of the lubricating mucus (Richards, 1974). A receptor-secretory function with paracrine action has also been attributed considering these cells as neuroendocrine-like, capable of producing bioactive substances (Licata et al., 1994, 1998, 2000).

The aim of this study is to characterize the glycoconjugates of the glandular cells of the Lumbricus terrestris epidermis using a battery of four biotinylated lectins and to correlate their binding to the epidermal cells function.

\section{MATERIALS AND METHODS}

Local earthworms (L. terrestris) were killed and pieces of epidermis from cephalic, clitellar and and embedded in paraplast. $5 \mu \mathrm{m}$ thick sections were stained by the hematoxylin-eosin (H-E), alcian/blue/PAS (AB/PAS) and Mallory methods. For lectin histochemistry, small tissue pieces were fixed at room temperature for $6 \mathrm{~h}$ in $4 \%$ paraformaldehyde (Merck, Darmstadt), in $0.1 \mathrm{M}$ phosphate buffer, $\mathrm{pH}$ 7.2. Tissue was dehydrated in graded ethanols and embedded in paraplast. Sections ( $5 \mu \mathrm{m}$ thick) were held for $10 \mathrm{~min}$ in $3 \%$ $\mathrm{H}_{2} \mathrm{O}_{2}$ to inhibit the endogenous peroxidase activity and for $5 \mathrm{~min}$ in $0.1 \mathrm{M}$ phosphate-buffered saline (PBS), $\mathrm{pH} 7.2$, containing $1 \%$ bovine serum albumin (BSA) to reduce background staining. Then the sections were incubated with each of the lectins $(20 \mu \mathrm{g} / \mathrm{ml})$ for $30 / 60 \mathrm{~min}$ at room temperature. The lectins used were: concanavalin A (ConA), peanut agglutinin (PNA), wheat germ agglutinin (WGA) and Ulex europaeus agglutinin I (UEA I); these lectins were bound to an avidinbiotin-peroxidase-complex (ABC) and visualized by diaminobenzidine $/ \mathrm{H}_{2} \mathrm{O}_{2}$. In control experiments, sections were incubated in the presence of the corresponding inhibitory sugar to test the specificity of lectin binding. At the end of the procedure, the sections were photographed with an Axiophot (Zeiss) photomicroscope (x40 or x63 objectives).

The lectins and sugars were obtained from Sigma (St. Louis, MO, USA).

\section{RESULTS}

The epidermis of L. terrestris consists of a monostratified epithelium in the cephalic and terminal regions (Fig. 1), and a pseudostratified epithelium in the clitellar region. In all epidermal regions are present supporting, basal, sensory and glandular mucous cells as reported in previous studies (Richards, 1973, 1974; Licata et al., 1998, 2000). The mucous cells (orthochromatic and metachromatic) are mainly present in the clitellar region, while neuroendocrine-like cells are more numerous in the cephalic and terminal regions.

\section{ConA}

In the epidermis of the postclitellar (Fig. 2) and terminal (Fig. 3) regions, the binding for this lectin was strong in the cell membranes and the 
dular cells. Moreover, only the mucus of the orthochromatic cells was positive to this lectin. The other cell types were always negative. In the clitellar region, numerous orthochromatic mucous cells were highly labelled with ConA. The cuticle was weakly labelled as shown in Fig. 3. The controls incubated with the correspondent inhibitory sugar always gave negative results (Fig. 4).

\section{PNA}

The mucus of the metachromatic glandular cells was only positive in the epidermis of the terminal (Fig. 5) and chephalic (Fig. 6) regions. In the control, the epidermis appeared negative (Fig. 7)

\section{WGA}

This lectin labelled the neuroendocrine-like cells (small granular cells), in the cephalic (Fig. 8) and terminal (Fig. 9) regions. The mucous glandular cells were always negative.

\section{UEA I}

This lectin labelled only the cuticle of the entire epidermis (Fig. 10). The control was negative.

\section{DISCUSSION}

The different patterns of the lectins binding observed in this study suggest different functions for glycoconjugates in the various cell types and in the whole epidermis of the earthworm, in addition to that of lubrication.

The positivity of the mucus of the orthochromatic cells to ConA, specific for mannose and glucose, and the positivity of the metachromatic cells to PNA, specific for galactose and B-D-gal(1-3)Nacetylgalactosamine, may be correlated with a possible role of these glycoconjugates in the defence of the epidermis, and in recognition and elimination of pathogenic agents.

In the epidermis of the boar (Tsukise and Yamada, 1981) and fishes (Mittal et al., 1995), it has been shown that the sulfated glycoconjugates can prevent the proliferation of pathogenic microorganisms. A similar function can be supposed for the mucus produced by the metachromatic cells in the epidermis of the earthworm.

A small quantity of sulfated groups in the respiratory epidermis of the earthworm can be considered ascertained in the airways of fishes (Jones, 1977; Reid, 1978). Thus, these molecules may be part of a defensive system which, in the mucous epithelia of invertebrates, should contribute to protective mechanisms.

The binding to PNA in the mucus of the metachromatic cells may indicate an involvement in electrolyte homeostasis, since the glycoconjugates specifically binding this lectin are known to play an important role in this activity (Zaccone et al., 1987). Diolic groups regulate the integrity and functionality of the membrane receptors in transduction of the transmembrane signal (Shinohara, 1977).

In the earthworm epidermis, WGA surprisingly labelled the small granular cells that are regarded as neuroendocrine-like cells. The sialic acid and Nacetylglucosamine residues (Alroy et al., 1984; Fischer, 1984; Pino, 1984; Podell and Vacquier, 1984) revealed by WGA contribute to the membrane structural stability (Katsuyama and Spicer, 1977) required for permeability (Quinton and Philpott, 1973) and cell to cell interactions. Thus they play an important role in the processes of ion transport, as also emphasized in the epidermis of teleosts (Fasulo et al., 1991). Their presence in polarized cells also suggest that transcellular transport could be facilitated by complex acidic carbohydrates (Schulte and Spicer, 1985). Moreover, WGA binding sites in the neuroendocrine cells may be correlated with the release of secretory granule contents which occurs by exocytosis in the paraneuronal cells (Fujita et al., 1988). Indeed, glycosaminoglycans are also reported in the set of secretory substances produced by neurons and paraneurons (Fujita et al., 1988).

The neuroendocrine-like cells of the earthworm epidermis are characterized by the presence of some bioactive substances (serotonin, endothelin, neuron-specific enolase), cytoskeletal (cytokeratin CK 18) and calcium-binding (S-100) proteins, which are regarded as markers of the diffuse neuroendocrine system (Licata et al., 1994, 1998, 2000). These cells with receptive and secretory functions (Fujita et al., 1988), probably play a regulatory role (with a paracrine modality) on the activity of the mucous glandular cells. It is also argued that, in the clitellum, the proteinaceous secretion of small granular cells interacts with the mucus of the ortho- and metachromatic cells to form a viscoelastic complex. 
UEA-I labelling in the cuticle of the entire earthworm body, and ConA and PNA in mucous cells of the clitellum may prevent the uptake of noxious substances during differentiation and the early phases of embryonic development, thus playing a prominent role in host-pathogen relationships.

In the future, efforts must be directed to understanding the functional aspects of the various cell types of the earthworm epidermis.

\section{REFERENCES}

Alroy J., Orgad U., Ucci A.A., and Pereira M.E.A.: Identification of glycoprotein storage disease by lectins: A new diagnostic method. J. Histochem. Cytochem. 32, 1280-1284, 1984.

Fasulo S., Licata A., Contini A., Ainis L., Mauceri A., and Zaccone G.: Peroxidase localization of lectin binding sites on plasma membrane of the surface epidermis in the Rusty Blenny, Blennius sanguinolentus. (Pallas, 1811). Acta Zoologica, 72(4), 217-222, 1991.

Fletcher T.C.: Defence mechanism in fish. J. Histochem. Cytochem. 32, 681-689, 1978.

Fischer R.: Characterization of glycoconjugates of human gastrointestinal mucosa by lectins. J. Histochem. Cytochem. 32, 681-689, 1984.

Fujimoto T., and Ogawa K.: Cell membrane polarity in dissociated frog urinary bladder epithelial cells. J. Histochem. Cytochem. 31, 131-138, 1983.

Fujita T., Kanno T., and Kobayashi S.: The Paraneuron. Springer-Verlag, Tokyo, 1988.

Glick M.C., and Flowers H.: Surface membranes. In: The glycoconjugates. M.I. Horowitz, and Pigman W., eds. Academic Press, New York, London, pp. 337-384, 1978.

Harris J., and Hunt S.: Epithelial mucins of the Atlantic salmon (Salmon salar L.). Biochem. Soc. Trans. 1, 153-155, 1973.

Hughes G.M.: Functional morphology of fish gills. In: Epithelial transport in lower vertebrates. B. Lahlon, ed. Cambridge University Press, London, pp. 15-36, 1980. ic acid at the surface of the cell. In: Biological roles of sialic acid. A. Rosemberg, and Schengrund C.L., eds. Plenum Press, New York, London, pp. 201-238, 1976.

Jones R.: Modification of mucus in animal models of disease. Adv. Exp. Med. Biol. 89, 397-412, 1977.

Katsuyama T., and Spicer S.S.: A cation-retaining layer in the alveolar-capillary membrane. Lab. Invest. 36, 428-435, 1977.

Kirschner L.B.: External changed and $\mathrm{Na}^{+}$regulation. In: Osmotic and volume regulation. Alfred Benzon Symposium 11. Academic Press, New York, pp 310-321, 1978.

Licata A., Mauceri A., Ricca M.B., Lo Cascio P., Ainis L., and Martella S.: Cytokeratin distribution patterns in the epidermis of the earthworm Lumbricus terrestris L. (Annelida, Oligochaeta): a preliminary immunohistochemical study. Animal Biol. 3, 165-171, 1994.

Licata A., Mauceri A., Ainis L., Martella S., Ricca M.B., Lauriano E.R., and Amato A.: Immunohistochemical localization of bioactive substances in the epidermis of the earthworm Lumbricus terrestris (Annelida, Oligochaeta). Eur. J. Histochem. 42, 303-308, 1998.

Licata A., Mauceri A., Ricca M.B., Lo Cascio P., Martella S., and Amato A.: Immunohistochemical localization of calcium-binding proteins ( $\mathrm{CaBPs})$ in the epidermis of the earthworm Lumbricus terrestris (Annelida, Oligochaeta). Acta Histochem. 102, 1-8, 2000.

Mittal A.K., Fujimori O., Ueda H., and Yamada K.: Carbohydrates in the epidermal mucous cells of the fresh-water fish Mastacembelus pancalus (Mastacembelidae, Pisces) as studied by electron microscopic cytochemical methods. Cell Tissue Res. 280, 531-539, 1995.

Navas P., Villalba I.M., Buron M.I., and Garcia-Herdugo G.: Lectins as markers for plasma membrane differentiation of amphibian keratinocytes. Biology of the Cell 60, 225-234, 1987.

Pino R.M.: Ultrastructural localization of lectin receptors on the surface of the rat retinal pigment epithelium. Decreased sensitivity of the avidin-biotin method due to cell surface charge. J. Histochem. Cytochem. 32, 862-868, 1984.

Pisam M., and Ripoche P.: Redistribution of surface macromolecules in dissociated epithelial cells. J. Cell Biol. 71, 907920, 1976.

Figs. 1/10 - (1)A general view of the unmodified epidermis of the earthworm Lumbricus terrestris: orthochromatic (OC) and metachromatic (MC) mucous cells. Stained by the Mallory method. x490. (2)Postclitellar region of L. terrestris showing orthochromatic mucous cells (OC), cell envelopment of the metachromatic mucous cells (arrowheads) and the cuticle labelled slowly with ConA. x490. (3)Terminal region where orthochromatic mucous cells (OC), membranes of metachromatic cells (arrowheads) and cuticle are positive to ConA. x490. (4) As control to ConA, the sections of the postclitellar region were preincubated with its specific sugar. The epidermal cells are unstained. Interferential phase contrast observation. x490. (5)Terminal region where metachromatic mucous cells (MC) are positive to PNA. x490. (6)Metachromatic mucous cells (MC) are positive to PNA in the cephalic region. $x$ 490. (7)As control to PNA, the section of the cephalic region was preincubated with its specific sugar. The epidermal cells show no labelling. x650. (8)Cephalic region with neuroendocrine-like cells reactive to WGA (arrows). x850. (9)Neuroendocrine-like cells (arrows) strongly positive and more numerous than cephalic region with WGA in the terminal region. x650. (10)Only the cuticle is positive to UEA-I. $x 490$. 
the acrosome reaction in Strongylocentrotus purpuratus sperm by binding a $210,000-$ mol-wt membrane protein. J. Cell Biol. 99, 1598-1604, 1984.

Quinton P.M., and Philpott C.W.: A role for anionic sites in epithelial architecture. Effect of cationic polymers on cell membrane structures. J. Cell Biol. 56, 787-797, 1973.

Reid L.: Animal models in clinical disease. In: Respiratory tract mucus. R. Porter, Rivers J., and O'Connor M., eds. Ciba Foundation Symposium 54. North-Holland, Amsterdam, pp. 297-307, 1978.

Richards K.S.: The histochemistry of the large granular, orthochromatic, mucous cells of some lumbricides. Ann. Histochem. 18, 289-300, 1973.

Richards K.S.: The histochemistry of the metachromatic mucous cells of some lumbricides. Ann. Histochem. 19, 187197, 1974.

Richards K.S.: Epidermis and cuticle. In: Physiology of Annelids. P.J. Mill, ed. Academic Press, London N.Y., pp. 3361, 1978.

Schulte B.A., and Spicer S.S.: Histochemical methods for characterizing secretory and cell surface sialoglycoconjugates. J. Histochem. Cytochem. 35, 427-438, 1985.

Shinohara H.: On glycoproteins (in Japanese). Biochemistry 49, 1219-1237, 1977. ity of cell surface glycoconjugates - relation to differences in cell function. J. Histochem. Cytochem. 29, 994-1002, 1981.

Tsukise A., and Yamada K.: The histochemistry of complex carbohydrates in the scrotum of the boar. Histochemistry 72 , 511-521, 1981.

Villalba J.M., and Navas P.: Polarization of plasma membrane glycoconjugates in amphibian epidermis during metamorphosis. Histochemistry 90, 453-458, 1989.

Watt F., and Jones P.H.: Changes in cell-surface carbohydrate during terminal differentiation of human epidermal keratinocytes. Biochem. Soc. Trans. 20, 285-288, 1992.

Wendelaar-Bonga S.E.: The effect of changes in external sodium, calcium and magnesium concentrations on prolactin cells, skin and plasma electrolytes of Gasterosteus aculeatus. Gen. Comp. Endocrinol. 34, 265-275, 1978.

Zaccone G., Fasulo S., Lo Cascio P., Licata A., Ainis A., and Affronte R.: Lectin-binding pattern on the surface epidermis of Ambystoma tigrinum larvae. A light and electron study. Histochemistry 87, 431-438, 1987.

Zaccone G., Kapoor B.G., Fasulo S., and Ainis L.: Structur$\mathrm{al}$, histochemical and functional approaches of the epidermis of fishes. Adv. Mar. Biol., 40, 255-347, 2001. 